\title{
Left Ventricular Hypertrophy and Predictive Factors among Congolese Hypertensive Patients
}

\author{
Stéphane Méo Ikama*, Bernice Mesmer Nsitou, Jospin Makani, Louis Igor Ondze-Kafata, \\ Bertrand Fikhaem Ellenga-Mbolla, Thierry Raoul Gombet, Suzy Gisèle Kimbally-Kaky \\ Department of Cardiology, Brazzaville University Hospital Center, Brazzaville, Congo \\ Email: ^stephane.mikama@gmail.com
}

How to cite this paper: Ikama, S.M., Nsitou, B.M., Makani, J., Ondze-Kafata, L.I., Ellenga-Mbolla, B.F., Gombet, T.R. and Kimbally-Kaky, S.G. (2018) Left Ventricular Hypertrophy and Predictive Factors among Congolese Hypertensive Patients. World Journal of Cardiovascular Diseases, 8, 569-577.

https://doi.org/10.4236/wjcd.2018.812056

Received: November 4, 2018

Accepted: December 22, 2018

Published: December 25, 2018

Copyright $\odot 2018$ by authors and Scientific Research Publishing Inc. This work is licensed under the Creative Commons Attribution International License (CC BY 4.0).

http://creativecommons.org/licenses/by/4.0/

\begin{abstract}
A cross-sectional study of hypertensive patients was carried out in Brazzaville between January 2011 and December 2013. The objectives of the present study are to determine the different types of left ventricular hypertrophy $(\mathrm{LVH})$ and to identify the predictive factors of LVH. It included 556 hypertensive patients with $\mathrm{LVH}$, characterized by left ventricular mass index $($ LVMI $)>135 \mathrm{~g} / \mathrm{m}^{2}$ in men, and $>111 \mathrm{~g} / \mathrm{m}^{2}$ in women. Patients' sociodemographic data and echocardiographic parameters were gathered and analyzed. There were 342 males (61.5\%) and 214 females (38.5\%), with mean age $53.5 \pm$ 11.5 years. The indications of the test were hypertension initial evaluation in 402 cases $(72.3 \%)$, investigation of ischemic stroke in 62 cases $(11.2 \%)$, heart failure in 58 cases (10.4\%), dyspnea and chest pain in respectively 22 and 12 cases. Hypertension, old of $5.2 \pm 4.5$ years, was associated with overweight/obesity in 408 cases (73.4\%), physical inactivity in 325 cases (58.5\%), hypertension family history in 274 cases (49.3\%), diabetes mellitus in 76 cases (13.7\%), dyslipidemia in 63 cases (11.3\%), tobacco use in 9 cases $(1.6 \%)$. The prevalence of LVH was $49.4 \%$ and consisted into concentric LVH in 470 cases (84.5\%), eccentric LVH in 70 cases $(12.6 \%)$, and in 16 cases $(2.9 \%)$, it was a concentric left ventricular remodeling. Age, male gender, seniority of hypertension and treatment were predictive factors of LVH. The latter is the most predominant abnormality in the echocardiographic profile of Congolese hypertensive patients. Efficient management on hypertension will lead to reducing its morbidity and mortality.
\end{abstract}

\section{Keywords}

Arterial Hypertension, Left Ventricular Hypertrophy, Predictive Factors, Congo 


\section{Background}

Arterial hypertension (HTN) is a major problem of public health in the world, and more particularly in sub-Saharan Africa, with a persistently increasing prevalence, forecast of almost 150 million cases by 2025 [1]-[7]. In Congo, its prevalence was estimated at $32.5 \%$ in Brazzaville [8]. In sub-Saharan Africa, the management of HTN remains difficult because of its ignorance and the modest social conditions of the populations [9] [10] [11]; its severity exposes to many complications including left ventricular hypertrophy (LVH) [12]. Left ventricular hypertrophy constitutes an independent risk factor of cardiovascular and cerebrovascular complication. $\mathrm{LVH}$ is measured by electrocardiography, echocardiography, and magnetic resonance imaging. In order to improve the management of the Congolese hypertensive patients, we carried out this study to determine the different types of left ventricular hypertrophy ( $\mathrm{LVH})$ among Congolese hypertensive patients, and to identify the predictive factors of LVH.

\section{Patients and Methods}

It was about a cross-sectional study, analytical, carried out with Brazzaville between January 2011 and December 2013, that is to say 36 months. It included a consecutive series of 556 of the 1.125 hypertensive, known and treated patients, having had a left ventricular hypertrophy ( $\mathrm{LVH})$, diagnosed at the transthoracic echocardiography (TTE) either within the framework of an initial evaluation of hypertension, or for any symptom such as dyspnea, thoracic pain, or at the time of a complication (heart failure, stroke). The examinations were carried out with echographs of the brand Medical Kontron (ImagicMaestro, 2009) and Esaote (MyLab Class, 2012). The probe phased array of $2.5 \mathrm{MHz}$ was used. The sociodemographic data of the patients as well as the associated cardiovascular risk factors, the data related to the hypertension, and the echocardiographic parameters were collected by using a questionnaire, and were analyzed. Thus, several variables studied, in particular:

1) sociodemographic data: age, gender, socioeconomic level (weak, average, high according to ECOM investigation [13]);

2) associated cardiovascular risk factors: diabetes, overweight/obesity, tobacco addiction, dyslipidaemia, sedentariness;

3) data related to the HTN: seniority, concept of family HTN, antihypertensive protocol used (monotherapy, bitherapy, tritherapy, quadritherapy and more);

4) echocardiographic parameters:

- indication of the examination: initial evaluation of the HTN, symptom (dyspnea, thoracic pain) and complication (heart failure, stroke);

- measured parameters: interventricularseptal (IVS), LV posterior wall (LVPW) thickness, end-diastolic (EDLVD) and end-systolic (ESLVD) left ventricular diameters, left ventricular systolic and diastolic function, left ventricular mass (LVM). 
- the left ventricular mass (LVM) was measured according to the recommendations of the American Society of Echography (ASE), and was then calculated using the formula by Devereux [14]. Left ventricular hypertrophy $(\mathrm{LVH})$ was defined as a body surface area indexed LVM $(\mathrm{LVMI})>135 \mathrm{~g} / \mathrm{m}^{2}$ in men, and $>111 \mathrm{~g} / \mathrm{m}^{2}$ in women [14] [15].

- the relative wall thickness (RWT), defined by the 2 LVPW/EDLVD report, made it possible to distinguish the concentric $\mathrm{LVH}$ if $\mathrm{RWT} \geq 0.44$, of the eccentric LVH if RWT $<0.44$.

\subsection{Definition of the Concepts and Classification}

- the systolic dysfunction was defined by a left ventricular ejection fraction (LVEF) lowered to less than $50 \%$.

- the disorders of relaxation were defined by E/A $<0.5$, a DTE $>280 \mathrm{~ms}$, and an IVRT > $105 \mathrm{~ms}$;

- the disorders of the filling corresponding to a restrictive mitral profile, were defined by $\mathrm{E} / \mathrm{A}>2$, and a IVRT $\leq 90 \mathrm{~ms}$.

The various types of LVH were defined [16]:

- Normal left ventricule: normal LVMI, RWT $<0.44$;

- Concentric LVH: increased LVMI, RWT $\geq 0.44$;

- Eccentric LVH: increased LVMI, RWT <0.44;

- Concentric remodeling: normal LVMI, RWT $\geq 0.44$.

\subsection{Statistical Analysis}

The data were seized and analyzed with Epi-info 3.5.3 and SPSS 11.1 softwares. Chi-square and ANOVA tests allowed the comparison of the qualitative and quantitative variables. The research of the predictive factors of LVH was done using a logistic regression. The significance level was $\mathrm{p}<0.05$.

\section{Results}

\subsection{Epidemiological Trends}

They were 342 men (62.5\%) and 214 women (38.5\%), old on average of $53.7 \pm$ 10.2 years (range: 25 and 96 years), without difference between males and females $(52.4 \pm 12.6$ vs $53.5 \pm 11.5 ; \mathrm{p}=0.75)$. The socioeconomic level of the patients was average in 296 cases (53.2\%), weak in 196 cases (35.2\%), and high in 64 cases $(11.6 \%)$. The hypertension (HTN), old of $5.2 \pm 4.5$ years, was associated with overweight/obesity in 408 cases (73.4\%), physical inactivity in 325 cases (58.5\%), family history of HTN in 274 cases (49.3\%), diabetes mellitus in 76 cases (13.7\%), dyslipidaemia in 63 cases (11.3\%), and tobacco use in 9 cases (1.6\%), with a rate of office plurality of 2.7 risk factor by individual. Table 1 summarizes the main characteristics of the study population.

\subsection{Left Ventricular Hypertrophy (LVH) and Predictive Factors}

Main indications of the examination were initial evaluation of HTN in 402 cases (72.3\%), assessment etiologic of ischaemic stroke in 62 cases (11.2\%), heart 
Table 1. Characteristics of the study population.

\begin{tabular}{|c|c|c|c|c|}
\hline & $\begin{array}{c}\text { Men } \\
\mathrm{n}=342\end{array}$ & $\begin{array}{l}\text { Women } \\
n=214\end{array}$ & $\begin{array}{c}\text { All } \\
\mathrm{n}=556\end{array}$ & $\mathbf{p}$ \\
\hline Age, years & $53.7 \pm 10.2$ & $52.4 \pm 12.6$ & $53.5 \pm 11.5$ & 0.75 \\
\hline Seniority of HTN, years & $5.1 \pm 4.1$ & $5.3 \pm 5.2$ & $5.2 \pm 4.5$ & 0.81 \\
\hline \multicolumn{5}{|l|}{ Family history of HTN, $n(\%)$} \\
\hline Socioeconomic level, $n(\%)$ & $158(28.4)$ & $116(20.8)$ & $274(49.2)$ & 0.61 \\
\hline - -weak & $108(19.4)$ & $88(15.8)$ & $196(35.2)$ & \\
\hline - -average & $192(34.5)$ & $104(18.7)$ & $296(53.2)$ & \\
\hline - - -high & $42(7.6)$ & $22(4.0)$ & $64(11.6)$ & 0.0001 \\
\hline \multicolumn{5}{|l|}{ Antihypertensive protocol, $n(\%)$} \\
\hline - monotherapy & $19(3.4)$ & $12(2.1)$ & $31(5.5)$ & \\
\hline - $\quad$ bitherapy & $220(39.6)$ & $162(29.1)$ & $382(68.7)$ & \\
\hline - tritherapy & $89(16.0)$ & $34(6.1)$ & $123(22.1)$ & \\
\hline - quadritherapy and more & $14(2.5)$ & $6(1.1)$ & $20(3.6)$ & 0.05 \\
\hline \multicolumn{5}{|c|}{ Associated cardiovascular risk factors, $n(\%)$} \\
\hline - overweight/obesity & $240(43.2)$ & $168(30.2)$ & $408(73.4)$ & 0.0009 \\
\hline - physical inactivity & $142(25.5)$ & $183(33.0)$ & $325(58.5)$ & 0.008 \\
\hline - diabetes & $52(9.3)$ & $24(4.3)$ & $76(13.6)$ & 0.001 \\
\hline - dyslipidaemia & $43(7.7)$ & $20(3.6)$ & $63(11.3)$ & 0.025 \\
\hline - tobacco use & $7(1.2)$ & $2(0.4)$ & $9(1.6)$ & 0.005 \\
\hline
\end{tabular}

HTN: arterial hypertension.

failure in 58 cases (10.4\%), dyspnea and chest pain in 22 cases (3.9\%) and 12 cases $(2.2 \%)$ respectively. The echocardiographic examination, performed in 1.125 hypertensive patients, was pathological in 590 cases (52.4\%), and showed a hypertrophic cardiomyopathy (Figure 1 and Figure 2) in 556 cases (49.4\%). The left ventricular mass was an average of $289.5 \pm 94.2 \mathrm{~g}\left(164.5 \pm 52.6 \mathrm{~g} / \mathrm{m}^{2}\right)$ in the men, $247.6 \pm 72.4 \mathrm{~g}\left(143.2 \pm 42.7 \mathrm{~g} / \mathrm{m}^{2}\right)$ in the women; and the relative wall thickness was an average of $0.52 \pm 0.13$. Thus, the left ventricular geometry was normal in 535 cases (47.5\%). In the 556 cases of hypertrophic cardiomyopathy, the LVH was concentric in 470 cases (84.5\%), eccentric in 70 cases (12.6\%), and in 16 cases $(2.9 \%)$ it was about a concentric remodeling of the left ventricle. The left ventricular ejection fraction (LVEF) was an average of $71.7 \% \pm 8.5 \%$ (range: $58 \%$ and $90 \%)$. The disorders of relaxation were present in 251 cases (45.1\%). Concerning the research of the predictive factors of $\mathrm{LVH}$, in bivariate analyses, this one was correlated with the gender $(\mathrm{p}<0.0001)$, with the family history of HTN $(\mathrm{p}<0.0001)$, with the antihypertensive protocol used $(\mathrm{p}<0.0001)$, and with the dyslipidemia $(p=0.0002)$. In multivariate analysis, it arose that only the age $(\mathrm{p}=0.0001)$, the male gender $(\mathrm{p}<0.0001)$, the seniority of HTN $(\mathrm{p}<$ 0.0001 ), and the nature of the treatment, reflection of the severity of the HTN, were predictive factors of the LVH (Table 2).

\section{Discussion}

In our study, the HTN constitutes the first indication of the echocardiographic 


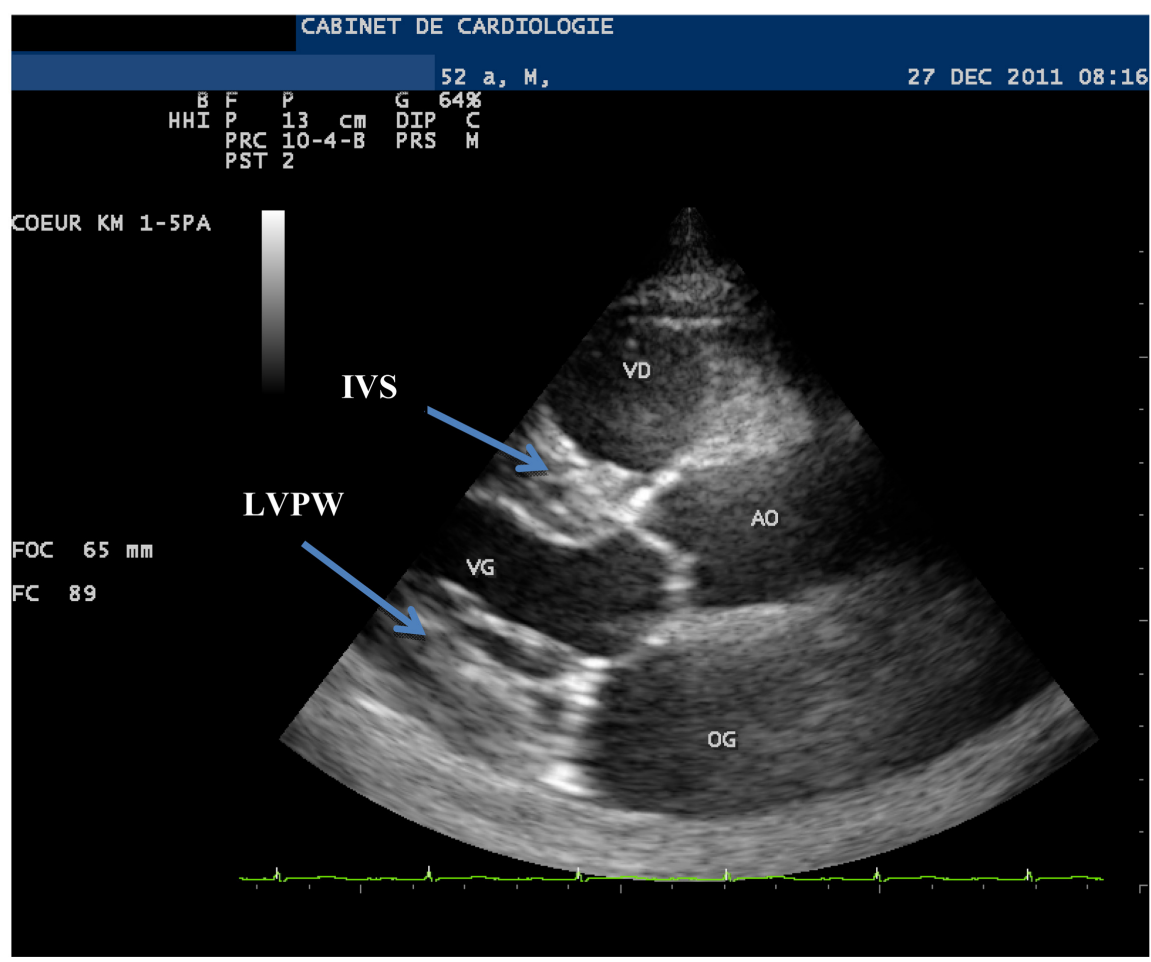

Figure 1. Transthoracic echocardiography, bidimensionnal mode, standard parasternal view, showing a concentric left ventricular hypertrophy (interventricularseptal [IVS] and LV posterior wall [LVPW]), in a 52 old-year hypertensive subject.

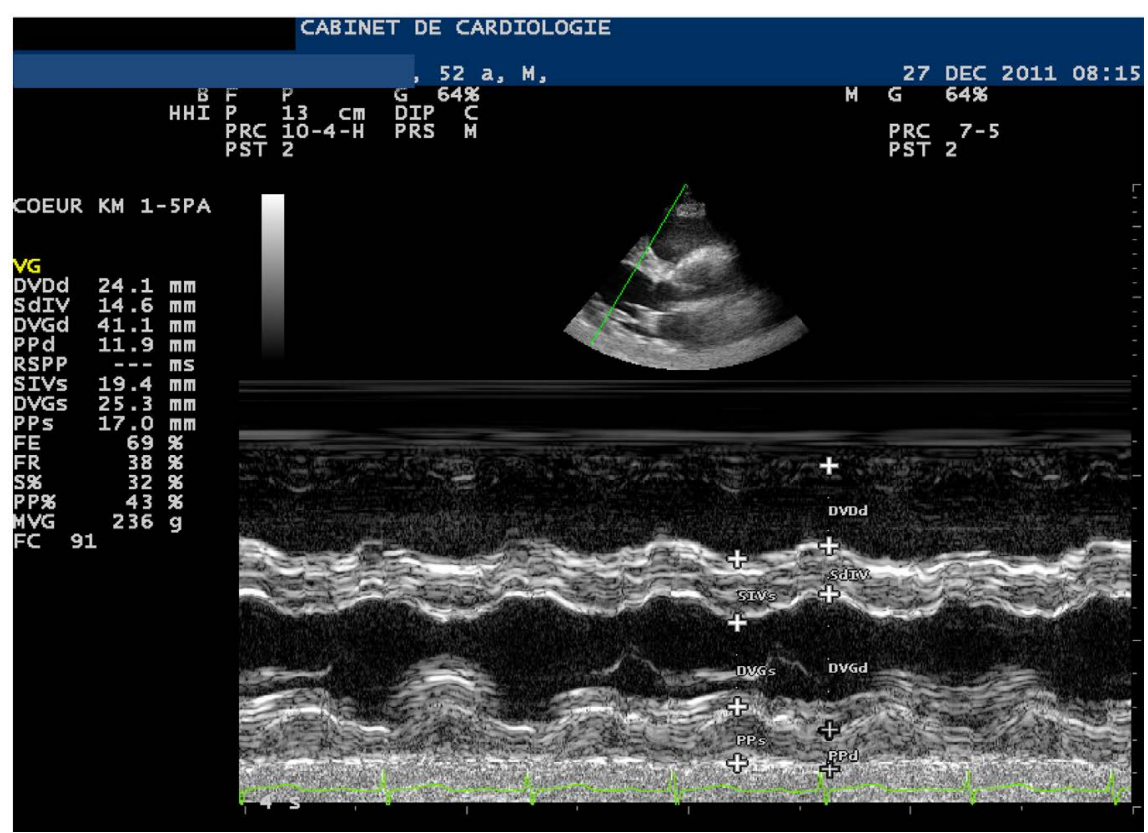

Figure 2. Transthoracic echocardiography, TM mode, standard parasternal view, showing an aspect of hypertrophic cardiomyopathy, in a 52 years hypertensive subject.

examinations with $61.4 \%$ of the cases. This report was raised at the Institute of Cardiology of Abidjan, where the HTN accounted for $49.2 \%$ of the echocardiographic indications [17], testifying to the importance of this pathology in 
Table 2. Logistic regression of left ventricular hypertrophy.

\begin{tabular}{ccc}
\hline Variables & OR (IC 95\%) & $\mathrm{p}$ \\
\hline Age & $1.02(1.01-1.04)$ & 0.0001 \\
Seniority of hypertension & $1.08(1.04-1.12)$ & $<0.0001$ \\
Diabetes (yes/no) & $1.06(0.69-1.62)$ & 0.7730 \\
Male gender & $1.85(1.42-2.40)$ & $<0.0001$ \\
Weaksocioeconomiclevel & $1.42(0.93-2.18)$ & 0.0993 \\
Averagesocioeconomiclevel & $1.75(1.21-2.52)$ & 0.0028 \\
Quadritherapy and more & $4.41(1.59-12.1)$ & 0.0042 \\
Sedentariness (yes/no) & $1.05(0.80-1.37)$ & 0.7018 \\
Overweight/obesity (yes/no) & $1.24(0.92-1.67)$ & 0.1515 \\
Tritherapy & $2.60(1.48-4.55)$ & 0.0008
\end{tabular}

sub-Saharan Africa. The African hypertensive patients are young, with a median age of $53.7 \pm 10.2$ years in our series, similar to those brought back to Cameroon and in Ivory Coast $(54.9 \pm 12.6$ years and $55.7 \pm 13.2$ years respectively) [16] [17]. Association with other cardiovascular risk factors is frequently reported, making these patients of the cardiovascular high-risk subjects. At the African black, the severity of HTN predisposes with occurred of the complications, often early, with the row of which left ventricular hypertrophy (LVH). In our series, the LVH was found at about half of the hypertensive patients, with a male prevalence. It is the same in most African series [18]-[23], with frequencies varying between $40 \%$ and $63 \%$, variability due to the methodological differences, making sometimes difficult any comparison. In the Framingham study [24] having related to 4.970 hypertensive patients, the frequencies of the LVH were $17.6 \%$ and $14.2 \%$ respectively among the men and women, by far lower than those noted among black hypertensive patients African, testifying to a particular predisposition in keeping with the genetic and racial factors [24]. As for the diastolic dysfunction, it is frequent, early appearing before even the installation of the LVH. The disorders of relaxation are dominating, such is the case in our series, found in a little less than half of the cases, of the $40 \%$ reported near in the North-African series [21]. The LVH has a multifactorial origin. Indeed, in addition to the HTN, certain factors considered as starting or modulating, can intervene in the genesis of the LVH. Among them, appear the sex, the age, the weight, the genetic and racial factors (the HTN is more frequent in the black race), the neurohormonal factors [25]. In our series, the age, the male gender, seniority of HTN, and its severity attested by the antihypertensive protocol (tritherapy or quadritherapy and more), were predictive LVH. Some of these factors, in particular the age, the gender, the seniority of the HTN, the arterial systolic pressure level, and others, such as obesity, hyperuricemia and alcohol, were identified like predictive factors of the LVH in African and Asian series [22] [26] [27]. 


\section{Limits of the Study}

The frequency of left ventricular hypertrophy brought back in our study is probably underestimated, if one takes account of the recent standards, defined by the learned societies, in particular the ESC/ESH with LVMI $>115 \mathrm{~g} / \mathrm{m}^{2}$ at the man, and $>95 \mathrm{~g} / \mathrm{m}^{2}$ at the woman. Also, certain data relating to the level of blood pressure, the rate of uric acid, like the consumption of alcohol, not collected at inclusion, did not allow a broader research of the predictive factors of left ventricular hypertrophy.

\section{Conclusion}

This study has shown that the left ventricular hypertrophy is a frequent presentation of hypertension disease among Congolese patients. The effective management of hypertension would make it possible to reduce the still heavy morbid-mortality which is ascribable for him, from where needs for the preventive measures, based on the medicamentous treatment and the therapeutic education of the patients.

\section{Conflicts of Interest}

The authors declare no conflicts of interest regarding the publication of this paper.

\section{References}

[1] Lawes, C.M., Vander Hoorn, S., Law, M.R., Elliott, P., MacMahon, S. and Rodgers, A. (2006) Blood Pressure and the Global Burden of Disease 2000. Part 1: Estimates of Blood Pressure Levels. Journal of Hypertension, 24, 413-422. https://doi.org/10.1097/01.hjh.0000199801.72563.6f

[2] Lawes, C.M., Vander Hoorn, S., Law, M.R., Elliott, P., MacMahon, S. and Rodgers, A. (2006) Blood Pressure and the Global Burden of Disease 2000. Part II: Estimates of Attributable Burden. Journal of Hypertension, 24, 423-430. https://doi.org/10.1097/01.hjh.0000209973.67746.f0

[3] Opie, L.H. and Seedat, Y.K. (2005) Hypertension in Sub-Saharan African Populations. Circulation, 112, 3562-3568. https://doi.org/10.1161/CIRCULATIONAHA.105.539569

[4] Kearney, P.M., Whelton, M., Reynolds, K., Muntner, P., Whelton, P.K. and He, J. (2005) Global Burden of Hypertension: Analysis of Worldwide Data. The Lancet, 365, 217-223. https://doi.org/10.1016/S0140-6736(05)70151-3

[5] Hendriks, M.E., Wit, F.W., Roos, M.T., Brewster, L.M., Akande, T.M., De Beer, I.H., et al. (2012) Hypertension in Sub-Saharan Africa: Cross-Sectional Surveys in Four Rural and Urban Communities. PloS ONE, 7, e32638. https://doi.org/10.1371/journal.pone.0032638

[6] Dalal, S., Beunza, J.J., Volmink, J., Adebamowo, C., Bajunirwe, F., Njelekela, M., et al. (2011) Non-Communicable Diseases in Sub-Saharan Africa: What We Know Now. International Journal of Epidemiology, 40, 885-901. https://doi.org/10.1093/ije/dyr050

[7] NCD Risk Factor Collaboration (NCD-RisC) (2017) Worldwide Trends in Blood 
Pressure from 1975 to 2015: A Pooled Analysis of 1479 Population-Based Measurement Studies with 19.1 Million Participants. The Lancet, 389, 37-55. https://doi.org/10.1016/S0140-6736(16)31919-5

[8] Kimbally-Kaky, G., Gombet, T., Bolanda, J.D., Voumbo, Y., Okili, B. and Ellenga-Mbolla, B. (2006) Prévalence de l'hypertension artérielle à Brazzaville. Cardiologie Tropicale, 32, 43-46.

[9] Adeloye, D. and Basquill, C. (2014) Estimating the Prevalence and Awareness Rates of Hypertension in Africa: Asystematic Analysis. PLoS ONE, 9, e104300. https://doi.org/10.1371/journal.pone.0104300

[10] Ataklte, F., Ergou, S., Kaptoge, S., Taye, B., Echouffo-Tcheugui, J.B. and Kengne, A.P. (2015) Burden of Undiagnosed Hypertension in Sub-Saharan Africa: A Systematic Review and Meta-Analysis. Hypertension, 65, 291-298.

https://doi.org/10.1161/HYPERTENSIONAHA.114.04394

[11] Dzudie, A., Rayner, B., Ojji, D., Schutte, A.E., Twagirumukiza, M., Damasceno, A., et al. (2017) Roadmap to Achieve 25\% Hypertension Control in Africa by 2025. Cardiovascular Journal of Africa, 28, 262-272. https://doi.org/10.5830/CVJA-2017-040

[12] Ojji, D.B., Libhaber, E., Atherton, J.J., Abdullahi, B., Nwankwo, A. and Sliwa, K. (2015) Risk-Factor Profile and Comorbidities in 2398 Patients with Newly Diagnosed Hypertension from the Abuja Heart Study. Medicine (Baltimore), 94, e1660. https://doi.org/10.1097/MD.0000000000001660

[13] Deuxième enquête congolaise auprès des ménages pour le suivi et l'évaluation de la pauvreté. (2011) Ministère du plan et de l'intégration. Vol. 1, Rapport du volet QUIBB-ECOM2, 142.

[14] Devereux, R.B., Liebson, P.R. and Horan, M.J. (1987) Recommendations Concerning the Use of Echocardiography in Hypertension and General Population Research. Hypertension, 9, 11-97-11-104. https://doi.org/10.1161/01.HYP.9.2_Pt_2.II97

[15] Devereux, R.B., Pini, R., Aurigemma, G.P. and Roman, M.J. (1997) Measurement of Left Ventricular Mass Methodology and Expertise. Journal of Hypertension, 15, 801-809. https://doi.org/10.1097/00004872-199715080-00002

[16] Kolo, P.M., Omotosho, A.B.O., Katibi, I.A., et al. (2008) Gender Diferencies in Left Ventricular Size and Geometric Patterns of Hypertension Subjects. Cardiology, 4, 11-15.

[17] Anzouan-Kacou, J.B., Siransy, E., Nchoh-Mottoh, M.P., Ekou, A., Bamba-Kamagaté, D. and Kadio, E.M. (2014) Echocardiographie transthroracique dans un institut de cardiologie à Abidjan (Côte d'Ivoire): Motifs et évaluation de la pertinence des indications. Annales de Cardiologie et d Angéiologie, 63, 1-6.

[18] Dzudie, A., Kengne, A.P., Mbahe, S., Menanga, A., Kenfack, M. and Kingue, S. (2008) Chronic Heart Failure, Selected Risk Factors and Co-Morbidities among Adults Treated for Hypertension in a Cardiac Referral Hospital in Cameroon. European Journal of Heart Failure, 10, 367-372. https://doi.org/10.1016/j.ejheart.2008.02.009

[19] Ojji, D.B., Opie, L.H., Lecour, S., Lacerda, L., Adeyemi, O. and Sliwa, K. (2013) Relationship between Left Ventricular Geometry and Soluble ST2 in a Cohort of Hypertensive Patients. The Journal of Clinical Hypertension, 15, 899-904. https://doi.org/10.1111/jch.12205

[20] Sarr, S.A., Babaka, K., Mboup, M.C., Fall, P.D., Dia, K., Bodian, M., et al. (2016) Aspects cliniques, électrocardiographiques et échocardiographiques de l'hypertendu 
âgé au Sénégal. Pan African Medical Journal, 25, 77.

[21] Ali-Tatar Chentir, N., Tir, Y., Ouabdesselam, L. and Chentir, M.T. (2016) Évaluation par l'échocardiographie des pressions de remplissage chez des patients hypertendus en insuffisance cardiaque à fraction d'éjection préservée dans une unité Nord Africaine d'hôpital de jour. Annales de Cardiologie et d'Angéiologie, 65, 197-202. https://doi.org/10.1016/j.ancard.2016.04.010

[22] Jaleta, G.N., Gudina, E.K. and Getinet, W. (2014) Left Ventricular Hypertrophy among Black Hypertensive Patients: Focusing on the Efficacy of Angiotensin Converting Enzyme Inhibitors. BMC Research Notes, 7, 45.

https://doi.org/10.1186/1756-0500-7-45

[23] Chillo, P., Lwakatare, J., Rieck, A.E., Lutale, J. and Gerdts, E. (2014) Prevalence and Covariates of Abnormal Left Ventricular Geometry in Never-Treated Hypertensive Patients in Tanzania. Blood Press, 23, 31-38. https://doi.org/10.3109/08037051.2013.791415

[24] Vaziri, S.M., Larson, M.G., Lauer, M.S., Benjamin, E.J. and Levy, D. (1995) Influence of Blood Pressure on Left Atrial Size. The Framingham Heart Study. Hypertension, 25, 1155-1160. https://doi.org/10.1161/01.HYP.25.6.1155

[25] Stewart, S., Wilkinson, D., Hansen, C., Vaghela, V., Mvungi, R., McMurray, J. and Sliwa, K. (2008) Predominance of Heart Failure in the Heart of Soweto Study Cohort: Emerging Challenges for Urban African Communities. Circulation, 118, 2360-2367. https://doi.org/10.1161/CIRCULATIONAHA.108.786244

[26] Wang, S.X., Xue, H., Zou, Y.B., Sun, K., Fu, C.Y., Wang, H., et al. (2012) Prevalence and Risk Factors for Left Ventricular Hypertrophy and Left Ventricular Geometric Abnormality in the Patients with Hypertension among Han Chinese. Chinese Medical Journal, 125, 21-26. https://doi.org/10.3901/JME.2012.16.021

[27] Sha, T., Huang, Y.Q., Cai, A.P., Huang, C., Zhang, Y., Chen, J.Y., et al. (2017) Prevalence and Determinants of Left Ventricular Geometric Abnormalities in Hypertensive Patients: A Study Based on the Updated Classification System of Left Ventricular Geometry. Hellenic Journal of Cardiology. 